DOI: $10.47743 /$ jss-2021-67-4-2

\title{
Munca şi noile ei contururi
}

\section{Labour and Its New Contours}

\section{Raluca Dimitriu ${ }^{1}$}

Rezumat: Doctrina caută de decenii separarea raporturilor de muncă de muncă de alte tipuri de raporturi juridice, cu scopul identificării obiectului dreptului muncii. Prezentul studiu merge un pas mai departe, încercând să identifice o definiţie a muncii însăşi. Asemeni universului în care trăim, şi universul digital este în expansiune, iar munca tinde să se disipeze în sutele de activităţi pe care le desfăşurăm zilnic, fără a mai exista o barieră fermă între ce anume este şi ce anume nu este propriu-zis muncă. Iar uneori considerarea unei activităţi ca nefiind muncă poate constitui o formă subtilă de exploatare. Nu mai este necesar ca beneficiarul muncii să îl plătească prost sau să nu îl plătească deloc pe cel care munceşte, nu mai este necesar să deghizeze contractul de muncă într-un alt contract; este suficient să îl convingă pe lucrător că, de fapt, ceea ce face el nu e muncă deloc.Voi încerca să explic această mutaţie şi să definesc câteva criterii de identificare a muncii.

Cuvinte-cheie: lucrător; dreptul muncii; digitalizare; istoria muncii

\begin{abstract}
The doctrine has been trying for decades to separate labour relations from other types of legal relations, with the purpose of identifying the object of Labour Law. Through the present study, we take a step forward, trying to identify a definition of labour itself. Similar to the universe we live in, the digital environment is also expanding, and "labour" tends to dissipate in the hundreds of activities we carry out every day, without any firm barrier between what is and what is not labour in itself. Moreover, sometimes, considering an activity as „not labour” can be a subtle form of exploitation. It is no longer necessary for the beneficiary of work to underpay or not to pay at all the person who is working; it is not necessary for the beneficiary of work to disguise the employment contract in another legal figure; it is sufficient to persuade the worker that, in fact, what she does in not work at all. I will attempt to explain this alteration, contouring at the same time several criteria for the identification of work.
\end{abstract}

Keywords: worker; labour law; digitization; the history of work

\section{Introducere. Munca - un construct cultural}

La prima vedere, munca pare un concept peren. Schimbătoare sunt raporturile juridice în baza cărora se prestează aceasta, dar actul în sine de a munci pare clar delimitat de orice altă activitate. De aceea, majoritatea cercetătorilor s-au

1 Profesor univ. dr., Academia de Studii Economice, București, e-mail: raluca.dimitriu@drept.ase.ro 
concentrat mai ales asupra diferenţierii muncii prestate într-un raport de subordonare de cea prestată în temeiul unui contract civil, în încercarea de identificare a graniţelor dreptului muncii. Aceste graniţe sunt în mişcare, dreptul muncii pierzând adesea teren prin falsa etichetare a unora dintre lucrători ca fiind „independenţi”, ceea ce a generat o extinsă literatură de drept al muncii menită tocmai să identifice criteriile muncii dependente şi să recupereze raporturile contractuale pierdute prin astfel de contracte deghizate. Tehnologia informaţiilor şi a comunicaţiilor este doar o unealtă, aşa cum multe unelte s-au succedat în timp. Indiferent de uneltele folosite, s-a spus, munca rămâne muncă, astfel încât interesul cercetătorului ar trebui să fie concentrat asupra raportului contractual în baza căruia este aceasta prestată.

Dar dacă nu numai munca dependentă, ci munca însăşi ar fi în schimbare? Dacă tehnologia nu ar fi doar un adjuvant, o modalitate în care munca se prestează, diferit doar formal de instrumentele folosite până acum, ci ar constitui sursa unei mutaţii esenţiale în însăşi definiţia muncii? Mai corespund definiţiile tradiţionale ale muncii contextului tehnologic şi social actual? Pentru a răspunde - fie şi parţial - la astfel de întrebări, vom trece în revistă diferitele etape istorice în definirea muncii şi raportarea socială la aceasta. Nu o vom face sistematic şi aplicat, ci pasager, doar cu scopul de a dovedi faptul că munca este un construct cultural, şi că nici definiţia acesteia, nici percepţia socială asupra muncii nu sunt constante în timp. Deşi în toate vremurile, în mentalul colectiv hărnicia a fost valorizată pozitiv, prin opoziţie cu trândăvia, ce anume, în mod concret, constituie muncă - a suferit schimbări continue. Vom vedea astfel că religia, revoluţia industrială şi, acum, cea digitală - au avut un anume impact asupra acestui construct. Vom căuta tot astfel unele criterii în funcţie de care să deosebim munca, în contextul actual, de alte activităţi. Şi vom semnala unele dintre efectele juridice ale acestor evoluţii.

\section{Iniţial...}

În societăţile timpurii, munca nu era foarte clar separată de celelalte sfere ale vieţii private. $\mathrm{Nu}$ se produsese încă divorţul dintre muncă şi viaţa de familie sau viaţa religioasă $\breve{2}^{2}$ iar activităţile necesare obţinerii de resurse nu erau privite ca fiind diferite de celelalte interacţiuni sociale ${ }^{3}$. Munca se desfăşura în comun, iar refuzul de a munci era sancţionat cu ostracizarea. Oamenii nu erau plătiţi pentru a munci; munca era o activitate naturală şi inevitabilă.

Odată cu apariţia societăţilor organizate mai complex, munca a început să se separe de celelalte activităţi, şi chiar tipurile de muncă au început să fie prestate de oameni diferiţi. A apărut specializarea muncii.

\footnotetext{
${ }^{2}$ H. Applebaum, The Concept of Work. Ancient, Medieval, and Modern, State University of New York Press, 1992, pp. 9-10.

${ }^{3}$ S. Zuboff, The Work Ethic and Organization, în J. Barbash, R.J. Lampman, S.A. Levitan, G. Tyler (coordonator), "The Work Ethic: A Critical Analysis”, Industrial Relations Research Association, Madison, WI, 1983, p. 153.
} 
Cu timpul însă, munca a început să fie disociată de activităţile superioare, cele dedicate gândirii şi folosofiei. Aristotel, la fel ca mulţi dintre gânditorii greci, considera că munca interferează cu îndatoririle cetăţenilor şi îi distrage de la activităţi mai virtuoase precum politica, arta şi filozofia ${ }^{4}$. Acestea nu puteau fi stăpânite decât printr-o educaţie îndelungată care necesită timp şi - fireşte - timp liber.

O lungă perioadă de timp, munca plătită a avut caracter ocazional şi marginal, societăţile întemeindu-şi necesarul de producţie pe munca sclavilor, devenită o parte importantă a economiei (mai ales în sec. V - III î.Hr. pentru Grecia şi sec. I î. Hr - sec. II d. Hr. pentru Roma), şi merită subliniat că munca lor nu era numai necalificată sau grea: sclavii desfăşurau şi activităţi intelectuale sau administrative. Astfel încât percepţia asupra muncii (de toate felurile) a devenit - prin contaminare - negativă; munca a început să fie privită cu un anume dezgust. Războiul şi politica erau îndeletniciri legitime ale cetăţenilor, dar asta deoarece ele nu erau percepute ca muncă; munca în sine era însă rezervată sclavilor şi necetăţenilor ${ }^{5}$. Munca îl coboară sau chiar îl înjoseşte pe om, credeau romanii în perioada imperiului, şi cred că aceştia ar fi fost foarte miraţi de valoarea pozitivă care avea ulterior să îi fie asociată muncii. In mod deosebit, a munci pentru altul era degradant şi umilitor. Pentru Cicero, munca plătită are vulgară şi nepotrivită pentru un cetăţean; plata muncii nu este altceva decât o formă de sclavaj. Iar Seneca spunea că, dacă printro neferită împrejurare a sorţii, ar ajunge să muncească, n-ar face o dramă din asta. Doar s-ar sinucide... ${ }^{6}$

\section{Impactul religiei asupra muncii}

Percepţia socială asupra muncii avea să fie ulterior puternic influenţată de religie. În creştinism, munca este blestem originar ("În sudoarea frunţii tale îţi vei mânca pâinea ta, până te vei întoarce în pământul din care eşti luat; căci pământ eşti şi în pământ te vei întoarce” - Facerea 3:19), dar şi datorie creştină; Sfântul Apostol Pavel spune de exemplu că „dacă cineva nu vrea să lucreze, acela nici să nu mănânce" (II Tes. 3, 10). În Evanghelia după Matei, Isus li se adresează în mod direct direct celor ce muncesc: „Veniţi la Mine, toţi cei trudiţi şi împovăraţi, şi Eu vă voi da odihnă” (Matei, 11:28).

Aceasta este o schimbare notabilă, care a dus la reconsiderarea muncii şi a celor ce o prestează. Deşi există un imens univers de nuanţe. În Calvinism, munca este o formă de glorificare a lui Dumnezeu, în timp ce Ortodoxia menţine o anume

\footnotetext{
${ }^{4}$ P.D. Anthony (coordonator), The Ideology of Work, Tavistock Publications, 1977, p. 17.

${ }^{5}$ Și aici nu intră doar munca manuală, ci chiar și activitățile intelectuale. Pentru Cicero, chiar și ocupații ca cea de doctor, arhitect sau profesor erau considerate nepotrivite pentru un cetățean. Singura excepție o formau juriștii, datorită legăturii cu activitatea politică, socotită onorabilă. H. Applebaum, op. cit, p. 96.

${ }^{6}$ După cum arată cu umor E. Carrère, în Împărăția cerurilor, Editura Trei, Bucureşti, p. 205.
} 
distanţare faţă de aceasta ${ }^{7}$, esenţa umană fiind socotită a fi mai curând contemplativă, „duminicală” ${ }^{8}$.

În Islam, devotamentul religios nu scuteşte credinciosul de muncă. Munca este considerată în centrul vieţii religioase ${ }^{9}$, fiind considerată concordantă cu comportamentul spiritual prescris şi privită uneori chiar ca formă de rugăciune $(\text { ibadah })^{10}$, atâta timp cât nu este prestată pentru faimă sau autoafirmare.

Raportarea la muncă se face în mod diferenţiat, în funcţie de ocupaţie.

Astfel, religia dictează tipul de muncă pe care fiecare individ are posibilitatea de a o presta, iar sistemele religioase au introdus obstacole diverse în practicarea anumitor meserii. În hinduism, de exemplu, castele sunt grupări ierarhice rigide, fiecăreia fiindu-i destinată o ocupaţie specifică: Brahmanii sunt preoţi şi învăţaţi, Kshatriyas sunt militari şi administratori, Vaishyas sunt comercianţi şi artizani, iar Shudras sunt muncitori manuali. Ca urmare, multe dintre profesii sunt inaccesibile castelor inferioare. Fiecăreia dintre caste - cărora li se adaugă „cei de neatins”, în afara sistemului - îi corespunde aşadar un anumit tip de muncă, iar alegerea liberă a profesiei este chiar şi astăzi, în unele regiuni, deşi posibilă juridic, imposibilă din cauza restricţiilor culturale.

În religia creştină, cele mai multe meserii şi ocupaţii sunt ocrotite de câte un sfânt (spre exemplu, arhitecţii şi constructorii sunt protejaţi de către Sfântul

7 Părintele Serghie Sevici (1903-1987) afirma: „Nu-i rău că truda nu-ți aduce nicio bucurie. Că n-am venit pe lume ca sa ne desfătăm. Ci suferința-i zestrea noastră pământească. Ba, rău este sa-ți placă munca ta, să-ți faci din ea un idol, să-i dai tot sufletul tău, lăsând de o parte ce e cu adevărat de preț. Veselie să-ți aducă lucrarea celor duhovnicești. Iar munca să-ți fie nevoință, spre încercare, cum este pentru călugăr ascultarea care-l rupe de la rugăciune și slujbe. Socotește-o uneltitoarea răbdării, că multă răbdare cere munca.”, [Online] la https://www.crestinortodox.ro/editoriale/munca-este-nefireasca-140821.html, accesat 1.10.2021.

Munca poate fi un mijloc, dar niciodată un scop în sine: „Apoi, când m-am uitat cu băgare de seamă la toate lucrările pe care le făcusem cu mâinile mele şi la truda cu care le făcusem, am văzut că în toate este numai deşertăciune şi goană după vânt şi că nu este nimic trainic sub soare.” (Eclesiastul, 2:11).

${ }^{8}$ V. Mureșan, Muncă şi libertate, în România culturală, anul 4, numărul 73, 16-30 noiembrie 2009, [Online] la http://www.romaniaculturala.ro/images/articole/muresan73verso09.pdf, accesat 1.10.2021: „Noi suntem oferiţi unei «Duminici» a libertăţii contemplative”, arată autorul. Munca „ne decade din vocaţia noastră supremă: contemplaţia”.

Această reticență față de valoarea spirituală a muncii poate fi întâlnită și la autori aparținând altor spații și epoci, cum ar fi Henry David Thoreau, care spunea în 1837, în Commencement Essay că „ar trebui ca ordinea lucrurilor să fie răsturnată; o zi pe săptămână să fie cea de trudă, prin care omul să-și câștige traiul cu sudoarea frunții, iar celelalte șase să fie Sabat, în care omul să se bucure de revelațiile Naturii” (Bloom’s Literary Criticism, 2008, p. 75).

${ }^{9}$ A.J. Ali, A. Al-Owaihan, Islamic work ethic: a critical review, Cross Cultural Management: An International Journal, Vol. 15 No. 1, 2008, pp. 5-19, https://doi.org/10.1108/ 13527600810848791 , p. 7, accesat 1.10.2021.

${ }^{10}$ I. Ahmad, Islamic Labour Code, [Online] la https://islamiclabourcode.org/work-ethicand-islam/, accesat 1.10.2021. 
Apostol Toma, minerii - de către Sfânta muceniţă Varvara, lucrătorii în piatră de către Sfântul Clement, doctorii de către Sfinţii Cosma şi Damian, pictorii de către Sfântul evanghelist Luca, meşteşugarii de către Sfântul Iosif etc.)

Cât priveşte însă obligaţia de plată a muncii, aici întâlnim abordări similare în marile religii. Profetul Mohamed afirma că va pleda personal împotriva celui care a beneficiat de munca unui lucrător, fără a-l plăti, recomandând, într-un hadis foarte expresiv, „Plăteşte-i lucrătorului salariul înainte ca transpiraţia să i se usuce”. În creştinismul ortodox, „oprirea plăţii lucrătorilor” este un păcat „strigător la cer”.

În întreaga perioadă pre-industrială, munca este prestată în familia lărgită, în comunitate; este prin ea însăşi un mod de comunicare şi socializare.

\section{După revoluţia industrială}

O mutaţie esenţială în ceea ce priveşte munca este adusă cu sine de revoluţia industrială, cu care conceptul de „etică a muncii” şi modul ulterior de raportare la muncă este cel mai adesea asociat. Etica muncii are înţelesul de „atitudine pozitivă faţă de muncă"11 şi a fost deplin potenţată de etica protestantă. Munca a fost întotdeauna un mijloc pentru obţinerea celor necesare traiului, dar nu a avut până acum o valoare intrinsec morală.

A existat însă de la început o anumită ipocrizie în spatele de noţiunii de etică a muncii, mai ales în ceea ce priveşte marea masă a lucrătorilor săraci, pentru care munca era singurul mijloc de subzistenţă, astfel încât a apărut ca fiind necesară, cum s-a arătat ${ }^{12}$, construcţia unui sistem de valorizare a muncii, cu tonuri teologice, pentru ,justificarea” muncii.

În societatea occidentală, probabil cel mai important moment din perspectiva modului social de raportare la muncă l-a constituit Reforma. Ea adus cu sine conceptul de „etică a muncii”, pe care îl întâlnim şi astăzi, deşi secularizat.

Dreptul tradiţional al muncii s-a construit pe fundamentul fordist al raportului de muncă. Este vorba despre construcţia juridică în temeiul căreia lucrătorul investeşte cea mai mare parte a vieţii sale adulte în întreprindere, care devine un element al identităţii sale. El lucrează pe parcursul unui program determinat, la sediul unităţii angajatoare, alături de colegii săi, cu care constituie sindicate şi alte modalităţi de organizare, participând astfel la negocierea colectivă, la greve şi acţiuni sociale. Acesta este contextul în care s-a creat dreptul muncii, alcătuit din dispoziţiile contractelor colective de muncă astfel încheiate şi din legislaţia standardelor minime, de protecţie a lucrătorului dezavantajat de subordonarea în care se găseşte în raport cu angajatorul său. În acest context, lucrătorul ajunge să se identifice în societate prin profesia sa, prin locul său de muncă - pe

${ }^{11}$ D.J. Cherrington, The Work Ethic: Working Values and Values That Work, New York: Amacom (1980), p. 19.

${ }^{12}$ G. Tyler, The Work Ethic: a union view, în J. Barbash, R.J. Lampman, S.A. Levitan, G. Tyler (coord.), The Work Ethic: A Critical Analysis, Industrial Relations Research Association, Madison, WI, (1983), p. 198. 
care le percepe ca atribute generatoare de mândrie sau, dimpotrivă, de resentimente ori frustrare ${ }^{13}$.

Observăm aşadar că societatea s-a raportat în timp în moduri diferite la muncă; sclavii nu aveau nevoie de motivaţii ideologice pentru a munci, fiind supuşi constrângerii fizice pentru a o face. În timp, constrângerea fizică a fost înlocuită cu cea religioasă şi, mai apoi, cu cea moral-seculară.

\section{Astăzi...}

Astăzi, societatea poziţionează munca drept determinantă pentru împlinirea personală. Întrebarea „ce vrei să te faci când vei fi mare?” pe care o aude astăzi aproape fiecare copil, ar fi surprins un observator provenit din secolele trecute, când ideile de „carieră” şi „succes profesional” nu-şi făcuseră încă loc în sfera preocupărilor cotidiene. Capacitatea de muncă şi angajabilitatea sunt scopurile principale ale sistemului de educaţie, ale oricărui tip de tratament medical, ale politicilor sociale, ale sistemelor de reintegrare socială din penitenciare sau ale programelor de compensare a şomajului ${ }^{14}$. Ceea ce urmăreşte societatea de la individ este ca acesta să fie apt de muncă.

Bineînţeles, activităţile necesare pentru susţinerea vieţii sunt fundamentale (omul întotdeauna a trebuit să mănânce). Dar munca, aşa cum o înţelegem astăzi, abstractizată, independentă de formele ei particulare (arat, construit, vânat, gătit) are origini moderne. Până acum câteva secole, aspiraţiile, succesul, scopul în viaţă sau sentimentul de identitate erau regăsite în tradiţii şi credinţă, nu în muncă ${ }^{15}$.

Schimbarea accentului de pe muncă - în sensul de mijloc de asigurare a resurselor necesare traiului, pe muncă - în sensul de izvor de dezvoltare personală a modificat semnificativ percepția socială generală asupra muncii. Protestantismul şi, cu deosebire Calvinismul, a sanctificat munca, socotind-o un ideal spiritual prin ea însăşi. Iar societatea de astăzi, centrată cumva în jurul muncii, nu face decât să urmeze acest model. El a pătruns din spaţiul occidental influenţând etica muncii şi în ţările care, pe fondul tradiţional ortodox, nu valorizau munca în context spiritual.

Tradiţional, dreptul muncii se ocupă de reglementarea muncii - a activităţii prestate în raport de subordonare. Scapă normelor de drept al muncii activitatea prestată în raporturi de egalitate juridică, care formează obiect al dreptului civil. Dar ne găsim astăzi pe teritoriul unui conflict negativ de competenţă: munca prestată de ne-salariaţi, care nu se găsesc însă în relaţiii juridice de egalitate cu beneficiarul muncii nu este guvernată de dreptul muncii, nefiind prestată de salariaţi, dar nici propriu-zis dreptului civil, nefiind o muncă real independentă. Singura formulă juridică prin care aceste activităţi ar fi re-apropriate de dreptul

${ }^{13}$ R. Dimitriu, Dreptul muncii. Anxietăți ale prezentului, Editura Rentrop și Straton, București, 2016, p. 18.

${ }^{14}$ N. Glazer, Women's Paid and Unpaid Labor: The Work Transfer in Health Care and Retailing (Women in the Political Economy), Philadelphia: Temple University Press, 1993, p. 33.

${ }^{15}$ B. Hunnicutt, Work Is Our Religion And It's Failing Us, Huffpost, 18 mai 2018, [Online] la https://www.huffpost.com, accesat 1.10.2021. 
muncii ar fi cea a simulaţiei, atunci când se poate proba că în realitate contractul de muncă a fost deghizat într-un contract civil.

Problema este că există o serie de activităţi care nu sunt supuse niciunei reglementări. Ele nici nu sunt percepute ca fiind muncă, deşi produc profit unei anumite entităţi, iar la baza prestării lor se găseşte - uneori bine ascuns - un contract. Unele astfel de activităţi sunt sporadice, incidentale, astfel încât lipsindule elementul de repetabilitate care caracterizează îndeobşte munca, trec „pe sub radarul" analizei juridice. Altele sunt mai importante cantitativ, dar sunt de asemenea nereglementate mai curând din cauza dificultăţii de identificare a părţilor contractului pe baza căruia sunt prestate. În sfârşit, altele sunt nereglementate din cauza noutăţii lor, constituind expresia unor evoluţii tehnologice la care dreptul nu a reuşit încă să se adapteze.

\section{Cum a schimbat digitalizarea conceptul de muncă}

Cum arătam, conceptul modern de muncă a apărut odată cu revoluţia industrială, ca activitate plătită ce se desfăşoară într-un spaţiu diferit de propria gospodărie şi care este ferm separată de viaţa privată. Lucrătorul pleacă de acasă ca să muncească; în spaţiul destinat muncii dezvoltă relaţii sociale care sunt diferite de cele de familie, iar apoi se întoarce acasă pentru a-şi petrece timpul de repaus un mod de organizare a vieţii ce nu exista înainte de revoluţia industrială.

Digitalizarea a adus însă cu sine o nouă mutaţie asupra modului de raportare la muncă. Aceasta nu mai este neapărat o experienţă colectivă, ci solitară. Graniţele dintre viaţa privată şi cea profesională sunt blurate, deja lucrătorul digital a încarnat activitatea productivă în programul petrecut cu familia şi puţini sunt cei care mai reuşesc să traseze limite ferme între aceste două universuri.

Asemeni lui Benjamin Button, cu trecerea timpului, munca pare a se întoarce spre propria sa copilărie.

Într-adevăr, iată că astăzi munca prestată în cadrul familiei, în propria gospodărie, a început să aibă o relevanţă pe care nimeni nu bănuia că o va recăpăta în contextul societăţii moderne. Depărtarea fizică de colegii săi, fenomen preexistent, dar fără îndoială accentuat de criza Covid 19, metodele manageriale contemporane, orientate spre autonomie, ca şi relaţia tot mai directă cu clientul, au transformat lucrătorul într-un lup singuratic, ce îşi obţine resursele într-un context universal concurenţial şi căruia i se pretinde o atitudine mai curând antreprenorială. Aproape nimic din ceea ce era definitoriu pentru munca prestată în cuprinsul marilor companii industriale, care a prilejuit geneza dreptului muncii pe fundamentul solidarităţii dintre lucrătorii ce lucrau umăr lângă umăr, nu mai este indispensabil astăzi. Dacă privim de exemplu Recomandarea (nr. 198) din 2006 a OIM privind relaţiile de muncă, ca şi indicatorii socotiţi a fi determinanţi pentru identificarea unei relaţii de muncă, putem observa cât de mult s-a schimbat munca dependentă în ultimii 15 de ani.

Digitalizarea a schimbat nu numai modul în care munca este efectiv prestată, dar şi modul în care o percepem. Desprinderea de un spaţiu fizic de prestare a muncii poate conduce spre repoziţionarea muncii în întreaga noastră viaţă. Deja 
generaţiile cele mai recent intrate pe piaţa muncii nu mai valorizează munca aşa cum o făceau părinţii lor, ci tind să aşeze în centrul existenţei lor timpul liber şi experienţele de viaţă (nu neapărat profesională).

\section{Criterii de distingere a muncii de alte activităţi}

Literatura abundă de definiţii date muncii ${ }^{16}$. În psihologia muncii, munca reprezintă totalitatea manifestărilor umane conştiente, mentale şi/sau operaţionale, prin care omul acţionează asupra mediului, asupra lui însuşi şi a celorlalţi oameni în vederea satisfacerii trebuinţelor, intereselor, aspiraţiilor, realizării unor scopuri. Caracteristicile muncii sunt: „(a) munca este o activitate învăţată: munca nu este un simplu răspuns al organismului la stimuli de moment sau la solicitări ale instinctului, ci o activitate de îndeplinire a unor sarcini; (b) prin muncă omul îşi produce bunurile materiale necesare subzistenţei şi pe cale spirituale, deci în consecinţă ea este un factor esenţial în procesul de umanizare, socializare şi culturalizare a fiinţei umane; (c) este o activitate deliberată întrucât atât produsul, rezultatul muncii cât şi scopul sarcinii de muncă au fost construite mai întâi în plan mental, cu participarea întregului sistemul psihic uman. Scopul este elementul esenţial care declanşează, susţine şi determină felul activităţii de muncă" ${ }^{17}$

Dar care sunt elementele unei definiţii a muncii, în contextul de astăzi, marcat de evoluţiile tehnologice pe care le aminteam?

Voi începe prin a preciza care sunt elementele pe care nu cred că ar trebui să le cuprindă o astfel de definiţie.

Tradiţional, când ne gândim la muncă, avem în vedere o activitate mai curând grea, care durează o perioadă îndelungată, care are caracter repetitiv, pe care o prestăm cel mai adesea nu din plăcere, ci din necesitatea de a obţine resursele necesare existenţei. Tindem să asociem aşadar munca efortului şi neplăcerii, excluzând activităţile pe care le desfăşurăm din pasiune. $\mathrm{Cu}$ toate acestea, munca creativă nu este cu nimic mai puţin muncă. Faptul că resortul principal al desfăşurării unei munci îl constituie pasiunea permite uneori beneficiarilor muncii creative să profite de efortul lucrătorilor (care nici nu percep activitatea depusă de ei ca pe un efort, ci ca pe o necesară formă de expresie). Excluderea acestor activităţi din sfera muncii constituie în fond o formă de exploatare. De aceea, în definiţia muncii, aş elimina aspectele ce ţin de modul de raportare psihologică la aceasta şi aş spune că e nerelevant dacă e grea sau uşoară, plăcută sau neplăcută, sau dacă se confundă sau nu cu pasiunea celui care o prestează. $\mathrm{Cu}$ atât mai mult cu cât tehnologia eli-

${ }^{16}$ Potrivit dicționarului explicativ al limbii române, munca este „desfășurare a unei activități fizice sau intelectuale îndreptată spre un anumit scop; activitate prin care omul modifică și adaptează lucrurile din natură pentru satisfacerea trebuințelor sale”. Tot astfel, munca este definită ca fiind „,activitatea specifică, manuală și/sau intelectuală, prin care oamenii își utilizează aptitudinile fizice și spiritual în scopul producerii bunurilor, prestării serviciilor și executării lucrărilor cerute de trebuințele lor”. A se vedea, I.T. Ștefănescu, „Munca”, în Dicționar de dreptul muncii, Editura Universul Juridic, Bucureşti, 2014, pp. 250-251.

17 A se vedea A. Tabachiu, Psihologia muncii (curs), Editura Universităţii Politehnice, Bucureşti, 1997. 
mină cele mai multe din atributele negative care au caracterizat în mod tradiţional munca.

În al doilea rând, munca trebuie diferenţiată de ocupaţie. Ea are o sferă mult mai largă, şi nu încorporează doar activităţile destinate obţinerii de venituri necesare traiului. $\mathrm{O}$ activitate nu încetează a fi muncă doar pentru că nu este prestată cu regularitate.

Nerelevantă este şi măsura în care munca este sau nu plătită. Munca prestată în baza unui contract de muncă voluntară este numaidecât muncă, iar caracterul gratuit al contractului nu îi poate schimba această calitate.

Apoi, munca nu ar trebui opusă odihnei. Multe activităţi, deşi obositoare, intră totuşi în sfera recreativă sau de divertisment. Aşa a apărut noţiunea de „odihnă activă”, care presupune „desfăşurarea unor activităţi cu valenţe revitalizante sau alternarea unui fel de activitate cu altul"18.

În sfârşit, nu cred că referire la „mijloace de producţie” mai este obligatorie în definirea muncii astăzi, când digitalizarea a permis detaşarea acesteia de cele mai multe elemente materiale şi deplasarea ei în sfera exclusiv virtuală.

Dimpotrivă, în definirea muncii cred că ar trebui cuprinse ca elemente definitorii:

a) Munca este o activitate învăţată. Ea nu este prestată pe baze instinctive. $\mathrm{Cu}$ toate acestea, procesul de învăţare nu intră în conceptul de muncă, constituind o etapă preliminară muncii propriu-zise. În mod ideal, munca fructifică învăţarea. $\mathrm{Cu}$ toate acestea, în cazuri speciale, cum ar fi cel al artiştilor învăţarea (studiul la instrument, de exemplu) poate fi cu greu separată de procesul de fructificare a acestui efort, astfel încât aici graniţele pot deveni invizibile.

b) Munca presupune o alocare deliberată a energiei ${ }^{19} \ldots$

c) orientată către un scop. Scopul ar trebui să fie diferit de prestarea propriuzisă a activităţii respective.

d) Munca se prestează în baza unui act juridic (adesea, un contract)...

e) şi este solicitată de o altă persoană sau folositoare unei alte persoane (nu numai lucrătorului). $\mathrm{Cu}$ privire la acest element putem însă întâlni excepții, deoarece uneori munca nu este nici solicitată, nici folositoare la momentul la care este prestată, dar poate deveni astfel în timp. De exemplu, munca creativă este uneori prestată ca activitate voluptorie, din simpla dorinţă a artistului, fără să aibă la bază o ofertă contractuală. Ea va fi însă reconsiderată retroactiv, odată ce produsul muncii va forma obiect al unei astfel de oferte.

Aceste elemente vor putea sta la baza unei definiţii - fie şi provizorii - a muncii. Dar pornind de aici ne putem întreba: de ce ar fi necesar, din punct de vedere juridic, să definim munca? Să fie acesta un exerciţiu steril şi abstract?

Dimpotrivă. Definirea muncii şi determinarea graniţelor dintre aceasta şi alte tipuri de activităţi constituie o întreprindere fundamentală, mai ales în contextul

18 G.M. Hosu, Odihna activă, [Online] la http://www.psihologsportiv.ro/recuperarea/ odihna-activa/ accesat 1.10.2021

${ }^{19} \mathrm{~J}$. Suzman, Munca. O istorie a modului în care ne petrecem timpul (trad. de Iulia BerteaNani), Editura Publica, Bucureşti, 2021, p. 18. 
celor mai recente evoluţii tehnologice. Pentru că în realitate definiţiile tradiţionale ţin foarte puţin cont de aceste evoluţii.

$\mathrm{Nu}$ e vorba numai despre faptul că au apărut noi profesii, ci despre modul însuşi în care aceasta se prestează în prezent: crearea de conţinut online, activitatea desfăşurată de influenceri, recenziile la produsele cumpărate, activităţile desfăşurate în industria de jocuri - pot să constituie activităţi lucrative, care pot fi monetizate, chiar dacă cel mai adesea nu sunt monetizate chiar de lucrătorul însuşi. De altfel, uneori considerarea unei activităţi ca nefiind muncă poate constitui o formă subtilă de exploatare. Nu mai este necesar ca beneficiarul muncii să îl plătească prost sau să nu îl plătească deloc pe cel care munceşte, nu mai este necesar să deghizeze contractul de muncă într-un alt contract; este suficient să îl convingă pe lucrător că, de fapt, ceea ce face el nu e muncă deloc.

Să luăm de exemplu munca consumatorului. Ideea de „a-l pune pe consumator la muncă" nu este nouă: restaurantele McDonald's au transferat de mult clienţilor o parte din sarcinile de chelner ${ }^{20}$, iar la Ikea încă de decenii obiectele de mobilier sunt asamblate de către cumpărători. Dar tehnologizarea a permis o amplificare a acestui mod al companiilor de a extrage muncă gratuită din partea clienţilor, prin cele mai diverse modalităţi: citirea codului de bare de pe produse şi plata fără ajutorul casierilor, achiziţionarea online de bilete de transport, de spectacol, de spaţii de cazare, self check in-ul în aeroport şi multe altele. Acest proces a permis producătorilor să reducă cheltuielile cu personalul şi a atras disponibilizări masive. Munca prestată de consumator conduce la crearea unei anume relaţii personale cu producătorul, mai ales atunci când consumatorul este implicat nu numai în prestaţii necalificate, ci chiar în elaborarea de strategii, în furnizarea de idei pentru viitoare produse ale firmei sau pentru căi de îmbunătăţire a celor existente. Consumatorul este implicat şi în politicile de personal ale producătorului, solicitându-i-se feedback după aproape fiecare interacţiune cu personalul acestuia.

Nu ne preocupă la acest punct dacă efectul s-a resimţit şi în scăderea preţului produselor şi serviciilor, altfel spus, dacă clienţii au şi fost recompensaţi în vreun fel pentru munca depusă: uneori da, alteori nu. Chiar dacă aportul clienţilor nu duce la scăderea preţului, acest fapt nu e neapărat relevant în sine: nu ar fi primul caz de muncă neplătită. Dar chestiunea esenţială, din perspectiva pe care o avem aici în vedere este că adesea clienţii nici nu percep aceste operaţii ca fiind muncă. Şi aici e problema: avem de a face cu un tip de prestaţie ce nu numai că nu face obiectul unei înţelegeri contractuale distincte de achiziţionarea efectivă a produsului sau a serviciilor, dar - poate şi pentru că vorbim despre activităţi uşoare, de scurtă durată, chiar agreabile - nici nu poate fi pusă în discuţie ca „muncă”. Totuşi, dacă luăm în considerare criteriile pe care le-am propus la început - vom afirma fără tăgadă că activităţile consumatorului trebuie să intre în sfera

${ }^{20}$ D. Zwick, S.K. Bonsu, A. Darmody, Putting Consumers to Work: 'Co-creation' and new marketing govern-mentality, Journal of Consumer Culture, 2008; 8(2), pp. 163-196, https://doi.org/10.1177/1469540508090089, p. 166, accesat 1.10.2021. 
conceptului de muncă. După cum s-a arătat, „the 'free labor' of consumers is simultaneously voluntarily given and unwaged, enjoyed and exploited"21.

Implicarea consumatorului în procesul de elaborare, asamblare sau desfacere a bunurilor şi serviciilor pe care le achiziţionează, este, pe fond, o formă de exploatare ${ }^{22}$ nedeclarată şi neconştientizată ca atare.

Aşadar, o primă utilitate a definirii muncii este tocmai conştientizarea celui care o prestează cu privire la faptul că activitatea sa este producătoare de valori, care probabil sunt monetizate de către un beneficiar ce exploatează fie caracterul plăcut, fie durata scurtă, fie componenta de notorietate pe care o prezintă, fie componenta ludică a muncii, cu scopul obţinerii unui profit.

$\mathrm{O}$ a doua utilitate priveşte identificarea muncii dependente. Este cu neputinţă să vorbim despre distincţia muncii dependente de munca independentă fără a stabili mai întâi care sunt graniţele muncii înseşi. Abia apoi vom putea aplica criteriile de identificare a unei munci subordonate, ce interesează dreptul muncii, de munca guvernată de contractele de drept civil. Şi menţionăm în treacăt că aceste criterii ar trebui, la rândul lor revizitate, deoarece schimbarea de paradigmă adusă cu sine de digitalizare a făcut ca multe dintre criteriile consacrate (dintre cele prevăzute, de exemplu, de Recomandarea Organizaţiei Internaţionale a Muncii, pe care o aminteam mai sus) să cadă în desuetudine.

În sfârşit, a identifica munca poate produce consecinţe şi în ceea ce priveşte delimitarea timpului de muncă de timpul de odihnă. Sub aspect juridic, perioada de repaus nu are o definiţie, fiind un concept rezidual: constituie timp de repaus tot ceea ce nu cade sub definiţia timpului de muncă. Este desigur firesc ca o normă juridică de drept al muncii să se preocupe de timpul de muncă, nu de timpul de repaus, şi să decurgă doar pe cale de consecinţă care ar putea constitui timpul de odihnă, prin scăderea din zi a timpului de muncă. Dar acest mod de normare produce anume consecinţe şi în plan psihologic, întreaga existenţă a persoanei active fiind centrată pe timpul de muncă.

\section{Concluzii}

Nu numai prestarea muncii este diferită în fiecare etapă istorică, nu numai profesiile se schimbă de la o generaţie la alta, nu numai percepţia socială asupra muncii este în continuă mobilitate, dar munca însăşi, adică activitatea pe care o valorizăm social ca fiind „muncă” - reprezintă un construct cultural, specific unui anumit moment şi unei anumite regiuni.

De-a lungul istoriei au existat o serie de momente cheie, care au modificat definiţia muncii: de la descoperirea agriculturii la influenţa religiei şi de la revoluţia industrială la războaiele mondiale. Trăim astăzi de asemenea un astfel de moment, prin digitalizarea muncii, care a adus cu sine noi valenţe ale muncii creative, o estompare a graniţei între muncă şi divertisment, dar şi moduri fără precedent de

${ }^{21}$ T. Terranova, Network Culture: Politics for the Information Age, London and Ann Arbor, MI: Pluto Press, 2004 p. 73.

22 D. Zwick, S.K. Bonsu, A. Darmody, op. cit., p. 177. 
exploatare a activităţilor productive, prin deghizarea muncii în „non-muncă”. Este vital aşadar să identificăm o serie de repere de natură să ne permită să o definim. Am socotit astfel că munca reprezintă o activitate învăţată ce presupune o alocare deliberată a energiei, care este orientată către un scop, se prestează în baza unui act juridic şi este solicitată de o altă persoană sau folositoare unei alte persoane decât lucrătorul însuşi.

Definirea muncii nu prezintă utilitate numai din punct de vedere social, psihologic sau antropologic, ci şi juridic. Ea face posibilă limitarea ipotezelor de exploatare a muncii, prin conştientizarea celui care o prestează cu privire la posibilitatea ca activitatea sa, deghizată adesea în divertisment, să fie de fapt muncă. Deşi conştientizarea nu pune capăt exploatării, ea constituie totuşi un prim pas în această direcţie. Definirea muncii este tot astfel utilă şi pentru demersul ce preocupă autorii de drept al muncii de astăzi, anume diferenţierea muncii subordonate de cea independentă. Şi este poate utilă şi pentru clarificarea limitelor (între care, cum arăta Curtea de Justiţie a Uniunii Europene, „nu există zonă gri”) dintre timpul de muncă şi timpul de repaus.

\section{Referinţe}

Ali A.J., Al-Owaihan A., Islamic work ethic: a critical review, în Cross Cultural Management: An International Journal, Vol. 15 No. 1, 2008, pp. 5-19, https://oi.org/10.1108/ 13527600810848791

Anthony P. (ed.), The Ideology of Work, Tavistock Publications, 1977

Applebaum H., The Concept of Work. Ancient, Medieval, and Modern, State University of New York Press, 1992

Barbash J., Lampman R.J., Levitan S.A., Tyler G. (coord.), The Work Ethic: A Critical Analysis, Industrial Relations Research Association, Madison, WI, 1983

Cherrington D.J., The Work Ethic: Working Values and Values That Work, New York: Amacom, 1980

Dimitriu R., Dreptul muncii. Anxietăţi ale prezentului, Editura Rentrop şi Straton, Bucureşti, 2016

Glazer N., Women's Paid and Unpaid Labor: The Work Transfer in Health Care and Retailing (Women in the Political Economy), Philadelphia: Temple University Press, 1993

Hunnicutt B., Work Is Our Religion And It's Failing Us, Huffpost, 18 mai 2018

Iftichar A., Islamic Labour Code, Online

Ştefănescu I.T. (coord.), Dicţionar de dreptul muncii, Editura Universul juridic, Bucureşti, 2014

Suzman J., Munca. O istorie a modului în care ne petrecem timpul (traducere de Iulia BerteaNani), Editura Publica, 2021

Tabachiu A., Psihologia muncii (curs), Editura Universităţii Politehnice, Bucureşti, 1997

Terranova T., Network Culture: Politics for the Information Age, London and Ann Arbor, MI: Pluto Press, 2004

Zuboff S., The Work Ethic and Organization, în J. Barbash, R.J. Lampman, S.A. Levitan, G. Tyler (coord.), The Work Ethic: A Critical Analysis, Industrial Relations Research Association, Madison, WI, 1983

Zwick D., Bonsu S.K., Darmody A., Putting Consumers to Work: 'Co-creation' and new marketing govern-mentality în Journal of Consumer Culture, 2008; 8(2) pp. 163-196, https://doi.org/10.1177/1469540508090089 